\title{
Determining the Experience of a Swordsman and Sharpening Methods Based on Bone Cut Marks: A Pilot Study
}

\section{Cardle PM*}

MC Cardle Cultural Heritage, Archaeology, Australia

\begin{abstract}
The study sought to identify and compare characteristics of cut marks produced by an experienced swordsman wielding a traditionally made and polished katana (using a slicing action) with those produced by an inexperienced swordsman (using a hacking action) on three bone types (rib, flat, long) as well as to identify and compare striations in kerf walls produced by the different sharpening methods. Two different pig carcasses were struck (one carcass for each weapon type) and the resulting cut marks (experienced swordsman $n=27$; inexperienced $n=32$ ) were assessed and compared. The presence or absence of each of seven morphological characteristics were identified for each cut and recorded. A Scanning Electron Microscopic (SEM) analysis was undertaken on all kerf walls using Mikrosil negative casts. The morphological characteristics of striations were compared clinically and statistically between the two weapon types.

Micro curvature was more often present in cuts produced by an inexperienced swordsman compared to an experienced swordsman for the rib bones $(70 \%$ and $27 \%$ respectively, $p=0.09)$. For flat bones, although not statistically significant, flaking and feathering were identified only in cuts made by an inexperienced swordsman. For long bones, unilateral flaking was present in $50 \%$ of cuts produced by an inexperienced swordsman compared with only $10 \%$ of cuts made by an experienced swordsman $(p=0.02)$ while scoop defect was present in $25 \%$ of cuts made by an inexperienced swordsman and absent in all cuts of experienced swordsman $(p=0.22)$. Striations produced by the traditionally polished (sharpened) katana exhibited a smooth parallel step like pattern with a second smaller striation pattern on the top located along the step edge. Those produced by the display katana (factory machine sharpened) exhibited rough and mainly parallel striations with sharp edges.

The combination of morphology of katana cut marks, whether the cut marks were produced by a slicing or hacking action (experienced or inexperienced swordsman) or the weapon sharpening method (traditional or factory) will be of value to researchers in forensics and those investigating contemporary crime and war crimes.
\end{abstract}

Keywords: Archaeology; Swordsman; Bones

\section{Introduction}

The use of different weapons in war crimes, genocide and contemporary crime has led to the need to better identify cut marks made on bones by specific weapons and to develop standard investigation processes that may assist in the identification of a specific weapon used in such crimes, particularly in the absence of eyewitness accounts. Hacking trauma caused by hacking implements such as machetes, cleavers and broad swords are relatively understudied [15]. Whilst the katana has been used in modern crime, particularly the United Kingdom, it has been the subject of few studies, with all but one based on archaeological specimens [2,4,6-12]. The archaeological research identified cut marks made by a katana as being gashes, incisions and scratches [12]. Lewis [3] examined hacking trauma caused by six types of hacking implements (including a katana) and identified eight characteristics (shape, flaking, feathering, cracking, breakage, shards, aspect) that assist in the identification of the weapon class. Whilst hacking weapons can produce a wide range of morphologies, they are none the less distinguishable from other classes of bladed weapons. Previously identified characteristics of katana cut mark morphology include the presence of unilateral flaking, feathering and being ellipsoid in shape.

The research to date in relation to cuts produced by a katana has focused on using long bones and the skull but has yet to include other bone types (flat bones, ribs) and has focused on obtaining 'the perfect' sample to obtain clear results, at the exclusion of imperfect cut marks which are commonly found in forensic cases. Furthermore, previous research has not examined differences between an experienced swordsman wielding a katana used in the correct manner (slicing action) to that of an inexperienced swordsman wielding a katana used in a non-traditional manner (hacking). As an experienced swordsman is trained to use the weapon in a traditional manner, using a slicing action, it is expected that this action will be employed by an experienced swordsman regardless of whether the weapon was traditionally made or factory made. Similarly, Anin experienced swordsman is likely to have a 'natural' hacking action rather than an experienced slicing motion. The identification of a cut mark produced by an experienced or inexperienced swordsman has the potential to further assist in the identification of the perpetrator in investigations.

Scanning electron microscopy (SEM), a tool regularly utilised in archaeology, is becoming more common in forensic experiments [1317] and has proven a valuable tool in tool mark identification $[14,18]$ through identifying striations on kerf walls of bone caused by bladed weapons. The striations produced by a traditionally made and polished (sharpened) katana and those produced by a factory made and machine sharpened katana will also be examined.

The first aim was to devise the experiment as close to a real forensic

*Corresponding author: Cardle PM, MC Cardle Cultural Heritage, Australia, Tel: 0412702396; E-mail: mcheritage@iprimus.com.aup

Received September 18, 2017; Accepted September 25, 2017; Published October 04, 2017

Citation: Cardle PM (2017) Determining the Experience of a Swordsman and Sharpening Methods Based on Bone Cut Marks: A Pilot Study. J Anthropology Rep 2: 114

Copyright: @ 2017 Cardle PM. This is an open-access article distributed unde the terms of the Creative Commons Attribution License, which permits unrestricted use, distribution, and reproduction in any medium, provided the original author and source are credited. 
setting as possible. The second aim was to compare cut marks made on bones by an experienced swordsman wielding a katana in a traditional manner with those made by an inexperienced swordsman wielding a katana in a non-traditional manner. Thirdly, it was of interest to determine if differences are present in kerf walls using SEM between cut marks made by the two different weapon types (i.e. traditionally hand polished verses factory machine sharpened). Finally, as multiple bone types are often present in a forensic setting, three bone types were included in the research (long, ribs and flat) to examine and compare cut mark characteristics of the different bone types.

\section{Materials and Methods}

Juvenile domestic pig carcasses (Sus scrofa) were used as they are the closest representation of human flesh and bones and are most commonly used in forensic entomology. The sample included one whole carcass for each weapon which was purchased from the commercial sector and gutted, and the cavity stuffed with styrofoam to simulate the soft tissue usually present. To ensure consist ency of samples, all carcasses were male and weighed $45-50 \mathrm{~kg}$. The carcasses were suspended from a stable frame to simulate a standing attack.

All cuts were included, regardless of their condition (fractured, broken, crushed or incomplete) as it is uncommon that a 'perfect sample' is obtained from a forensic setting where hacking trauma is present. The experienced swordsman (16 years as a swordsman, ranked fourth degree black belt, registered with the world Aikido headquarters, Japan) wielded a traditionally made to order katana that was traditionally polished (sharpened) and wielded in a traditional manner (slicing action). The inexperienced swordsman wielded a standard, internet purchased, mass produced display katana that was factory sharpened and wielded in a non-traditional manner (hacking action).

Each swordsman was instructed to produce at least 6 cuts to each of three bone types (ribs, flat, long bones), producing a total of at least 18 cuts per swordsman and carcass. The experienced swordsman had no difficulty producing the required sample size and used the traditional slicing motion for striking the carcass. The inexperienced swordsman had some difficulty with aiming and striking the carcass and used a hacking action when striking the carcass.

The cut bones were removed from the carcases using a scalpel to remove the surrounding soft tissue, boiled in water to remove all remaining soft tissues and left to air dry for four weeks before assessment.

Visual observations of all cut marks were then undertaken and all characteristics noted and described. Each characteristic was recorded as absent, present bilateral or present unilateral. Qualitative and quantitative statistical analyses followed.

\section{Morphological Characteristic Comparison between Bone Types}

Seven morphological traits were identified during the examination of the samples and are described in Table 1. Of these, two are consistent with those described by Lewis (3) and five new characteristics were identified. Each cut mark was assessed based on the morphological analysis of each cut mark based on each of these characteristics being present or absent. Features such as cut length, width and depth were excluded as they were dependent on many factors, including, but not limited to, the strength of the person wielding the weapon. The presence or absence of shards was also excluded as shards are typically easily lost during decomposition and the defleshing/cleaning process and shape was also excluded as this is considered a subjective trait when shape is not so clearly defined on bones that have been subjected to trauma/fractures.

Although some characteristics described in Table 1 have also been found to be present on cut marks made by other hacking implements $[1,3]$, it is often possible to distinguish cut marks on bone produced by different large bladed hacking implements. For example, a machete produces a distinctive cut mark that may exhibit flaking, feathering and/or a scoop defect, but also chattering (a common machete trait). Whilst hacking weapons can produce a wide range of morphologies, they are none the less distinguishable from other classes of bladed weapons and often within their own class.

Both kerf walls (obtuse or inner side and the acute or outer sides of cuts) were examined using both macro and micro-analysis to identify cut characteristics. Mikrosil casts were taken of both kerf walls of all cuts and subject to Scanning Electron Microscopy (SEM). Samples were mounted on aluminium studs and coated with gold. The SEM was undertaken at The University of Newcastle, Electron Microscope and X-Ray Unit (NSW, Australia). The SEM analysis was guided by previous SEM analysis of bladed weapon cut marks on bone [14-17]. An initial analysis was undertaken using the Philips XL30 SEM+Oxford ISIS EDS utilising the SE (secondary electron) to allow for rudimentary comparison. The specimens exhibiting the clearest characteristics from each bone type were re-examined using the Zeiss Sigma VP FESEM+Bruker light element SSD EDS detector, again using the SE detector. The analysis was undertaken at varying working distances in order to obtain a clear image for comparative analysis [19].

\section{Statistical Analysis}

Cut characteristics were compared between weapon types using counts and percentages. Bivariate associations of weapon type by cut characteristics were assessed statistically using Pearson's chi-square tests of association and Fisher's exact tests when assumptions of the Pearson's chi-square test were not met.

Cluster analyses were also used to assess multiple characteristics

\begin{tabular}{|c|c|c|}
\hline Feature & Description & Photos \\
\hline Description & Records the breaking off of pieces of bone next to the mark, is defined by a flake scar present or a flake piece that fits the scar & Figure 4 \\
\hline Feathering & Records the lateral feathering, or rising up, of the external bone in a type of feathering pattern, and is still attached & Figure 5 \\
\hline Peeling & $\begin{array}{l}\text { Records the lateral raising or peeling away of the external bone surface next to the cut mark and is still attached to the bone. An } \\
\text { infraction (incomplete fracture) that is still attached at an unnatural angle }\end{array}$ & Figure 6 \\
\hline Micro-peeling & Records the micro lateral raising or peeling away of the external bone surface along the entry the cut mark and is still attached to the bone & Figure 7 \\
\hline Micro-curvature & Records the uniform micro curvature of bone at the entry & Figure 8 \\
\hline Scoop defect & $\begin{array}{l}\text { Records the presence of a fragment or wedge of bone removed during the removal of the blade, resulting in a concave defect with } \\
\text { multiple facets }\end{array}$ & Figure 9 \\
\hline Exit notch & Records the presence of a fragment or wedge of bone removed at the posterior of a complete cut mark & Figure 10 \\
\hline
\end{tabular}

Table 1: Cut mark characteristics. 
Citation: Cardle PM (2017) Determining the Experience of a Swordsman and Sharpening Methods Based on Bone Cut Marks: A Pilot Study. J Anthropology Rep 2: 114.

simultaneously in an attempt to develop a profile of cut characteristics to determine if characteristics were naturally clustered based on the experience or lack of experience of a swordsman. This analysis will help ascertain whether certain cut trait characteristics better discriminate between the experienced and inexperienced swordsman. The two-stage cluster analysis method was employed (Everitt et al.) with the Akaike Information Criterion used to select the most appropriate number of clusters. As the two-step cluster procedure is applied to categorical variables for the present study (the experience of the swordsman and the presence or absence of each cut trait), the log-likelihood measure is used to model the distances between the categorical variables. Cluster analysis does not differentiate between explanatory and response variables so all the variables from the first phase will be used in the second phase to determine whether the clusters naturally group trait characteristics according to weapon type. All statistical analyses were conducted using the statistical package SPSS v.23.0 [19].

\section{Results}

The experienced swordsman produced a total of 27 cut marks (11 rib; 6 flat; 10 long) and the inexperienced swordsman produced a total of 32 cut marks (10 rib; 12 flat; 10 long). Cut marks were further classified according to the aspect angle of the cut (perpendicular or glancing). The resulting number of cuts made by each swordsman by angle of cut is presented (Table 2).

\section{Rib bone}

Unilateral micro curvature was more than twice as likely present in cuts made by an inexperienced swordsman (70\%) compared to those made by an experienced swordsman (27\%) and was associated with borderline statistical significance $(\mathrm{p}=0.09)$. Expressing this relationship in terms of the odds ratio, the odds of detecting unilateral curvature in a cut mark on a rib bone when made by an inexperienced swordsman are 6 times the odds of an experienced swordsman. Flaking was slightly more likely present in cuts made by the experienced swordsman compared to the inexperienced ( $18 \%$ vs. 0$)$, whilst feathering and exit notch were more likely present for the inexperienced swordsmen compared with the experienced ( $10 \%$ vs. 0 and $100 \%$ vs. $82 \%$ respectively); however, none of these cut mark characteristics were statistically nor clinically significantly different based on swordsman experience at the $5 \%$ significance level (see). Peeling, chattering, micropeel and scoop were absent in cuts produced by all swordsmen so were therefore not useful for distinguishing between an experienced and inexperienced swordsman for the rib bone (Figure 1).

\section{Flat bone}

Examining the differences between an experienced and inexperienced swordsman for the flat bone, flaking was more likely present among the inexperienced compared with the experienced swordsmen ( $30 \%$ vs. $0 ; \mathrm{p}=0.25)$. Feathering and peeling were slightly more likely among the inexperienced compared with the experienced ( $20 \%$ vs. 0 and $10 \%$ vs. 0 respectively), although neither these nor any remaining characteristics were statistically nor clinically significantly different in terms of their occurrence based on experience $(\mathrm{p}>0.05)$.

\begin{tabular}{|c|c|c|c|c|}
\hline Swordsman & Angle of cut & Rib & Flat & Long \\
\hline \multirow{2}{*}{ Experienced swordsman } & Perpendicular & 0 & 5 & 1 \\
\cline { 2 - 5 } & Glancing & 11 & 5 & 5 \\
\hline \multirow{2}{*}{ Inexperienced swordsman } & Perpendicular & 1 & 7 & 6 \\
\cline { 2 - 5 } & Glancing & 9 & 5 & 4 \\
\hline
\end{tabular}

Table 2: Aspect sample numbers.

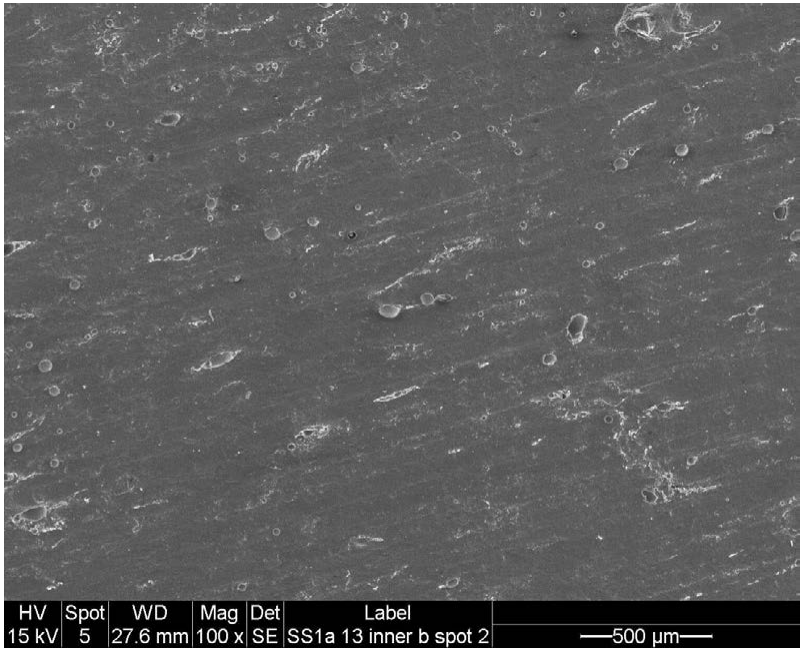

Figure 1: Long bone.

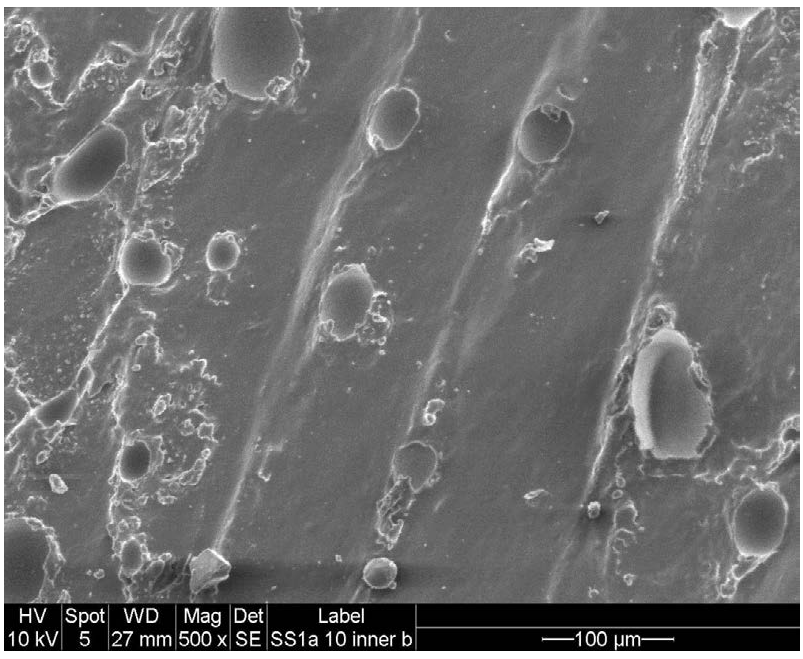

Figure 2: Rib bone.

The remaining traits, consistent with the rib bone were absent or mostly absent for all swordsmen while exit notch was present for all and thus not useful for identifying experience (Figure 2).

\section{Long bone}

Unilateral flaking is present in $50 \%$ of cut marks produced by an inexperienced swordsman compared with only $10 \%$ of cuts made by an experienced swordsman $(\mathrm{p}=0.02)$. Scoop defect, however, was present in $25 \%$ of inexperienced samples compared with none of the experienced samples $(\mathrm{p}=0.22)$. Unilateral micro curvature, although not statistically significant, was present in $33 \%$ of samples produced by an inexperienced swordsman and in only $10 \%$ of cuts produced by an experienced swordsman $(\mathrm{p}=0.32)$. This difference was considered clinically significant with respect to helping to identify experience. Exit notch was similar in prevalence based on experience $(\mathrm{p}=0.45)$ and consistent with the other two bones, chattering was absent for all cuts; so these traits were therefore not considered useful for distinguishing between an experienced and inexperienced swordsman. Similarly, peeling and micro-peeling were all or mostly absent for all swordsmen (Figure 3) 
Citation: Cardle PM (2017) Determining the Experience of a Swordsman and Sharpening Methods Based on Bone Cut Marks: A Pilot Study. J Anthropology Rep 2: 114.

Page 4 of 6

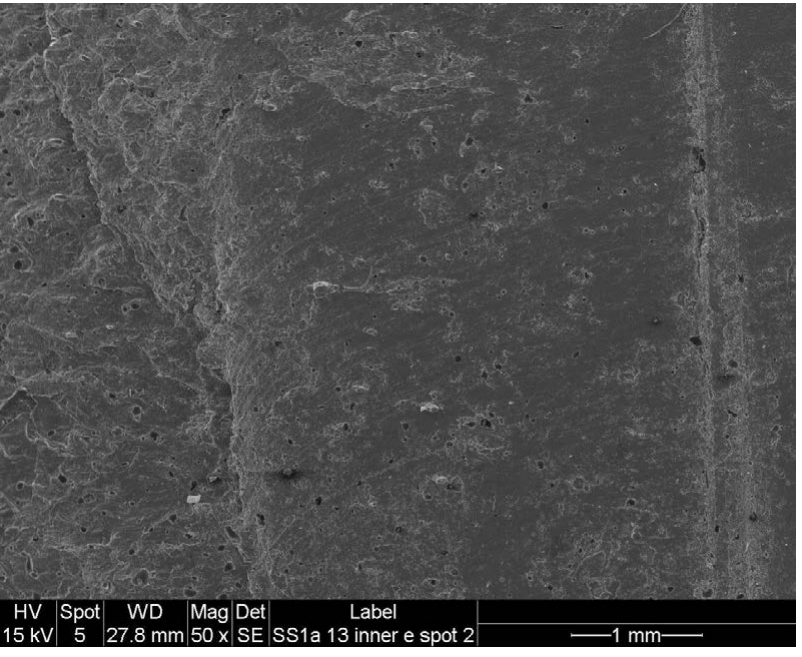

Figure 3: Long Bone.

A cluster analysis further assisted with summarising and highlighting the overall variable importance of cut mark characteristics based on experience. Applying the two-stage cluster analysis resulted in two clusters being identified for the rib bone. The silhouette measure of cohesion and separation of $60 \%$ implied moderate discriminative ability between cluster groups. The two cluster groups differed significantly from each other on curvature, with curvature absent in cluster 1 and present in cluster 2 . Flaking for cluster 1 was more likely present compared with cluster 2; although this effect was marginal (cluster importance 0.15); while feathering was less likely present in cluster 1 compared with cluster 2 (marginal effect: cluster importance of 0.15); while the swordsman was more likely experienced in cluster 1 compared with inexperienced in cluster 2 (cluster importance 0.24 ). After curvature, weapon contributed the most to the clusters (24\%), followed by flaking and feathering (both 15\%). This supports curvature as most likely present amongst the experienced swordsmen.

For the flat bone, the silhouette measure of cohesion and separation of $70 \%$ implied good discriminative ability between cluster groups. The two cluster groups differed significantly from each other on weapon type, with all the experienced swordsmen included in cluster 1 and $\mathrm{f}$ all of the inexperienced swordsmen in Cluster 2. Cut characteristics for cluster 1 (experienced swordsmen) were all absent (flaking and feathering), consistent with findings from the bivariate analyses. In contrast, for cluster 2 (inexperienced swordsmen), flaking was absent $70 \%$ of the time while feathering was absent $80 \%$ of the time. After weapon type, flaking contributed the most to clusters (21\%), followed by feathering (15\%). This confirms that for the experienced swordsman, flaking and feathering were more likely absent than for the inexperienced swordsman supporting some degree of difference between these measures according to experience.

Applying the cluster analysis to the long bone, the silhouette measure of cohesion and separation of 55\% implied moderate discriminative ability between cluster groups. The two cluster groups differed significantly from each other on flaking, with all samples for which flaking was present in cluster 1 and samples for which flaking was absent in Cluster 2. Cut characteristics for cluster 1 (when flaking was absent) also comprised the absence of scoop (100\%), absence of curvature (67\%) and an experienced swordsman (60\%); while for cluster 2 , flaking was present (100\%), curvature was absent (100\%), scoop was slightly more likely absent (57\%) and the inexperienced swordsmen was present $86 \%$ of the time. After flaking, scoop contributed the most to the clusters (39\%) followed by weapon type (24\%) with curvature contributing the least (19\%). This further highlights that for the cut made by the inexperienced swordsman in the long bone, flaking will most likely be present; scoop will more likely be present and curvature will more likely be absent, when compared to an experienced swordsman.

\section{Scanning Electron Microscopic (SEM) Analysis}

Striations caused by an experienced swordsman using a traditionally made and polished katana produced a smooth parallel step like pattern (Figures 4 and 5). These patterns were present on the cortical bone in all three bone types.

Further examination also revealed additional striations on top of the first striations along the step edge (Figures 6 and 7). These are also parallel but small spaces between each line. This is likely due to the polishing methods used to sharpen a traditional sword Striations produced by the inexperienced swordsman using a typical manufactured factory sharpened display katana produced very different patterns. Mainly parallel, the striations are rough in appearance and have a sharp/pointed edge at 50x to 100x magnification (Figures 8 and 9). These lines are not as clear as the experienced swordsman lines and is likely due to the factory sharpening methods. These patterns are present on the cortical bone of in all three bone types.

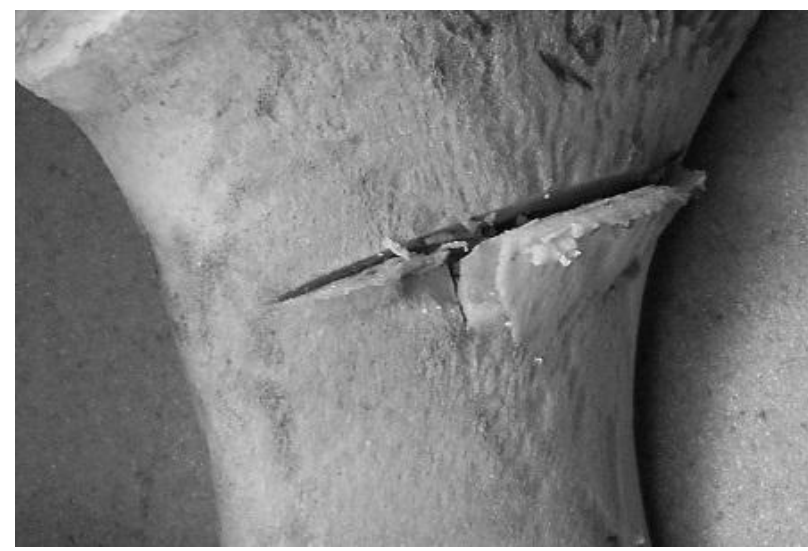

Figure 4: Records the breaking off of pieces of bone next to the mark, is defined by a flake scar present or a flake piece that fits the scar.

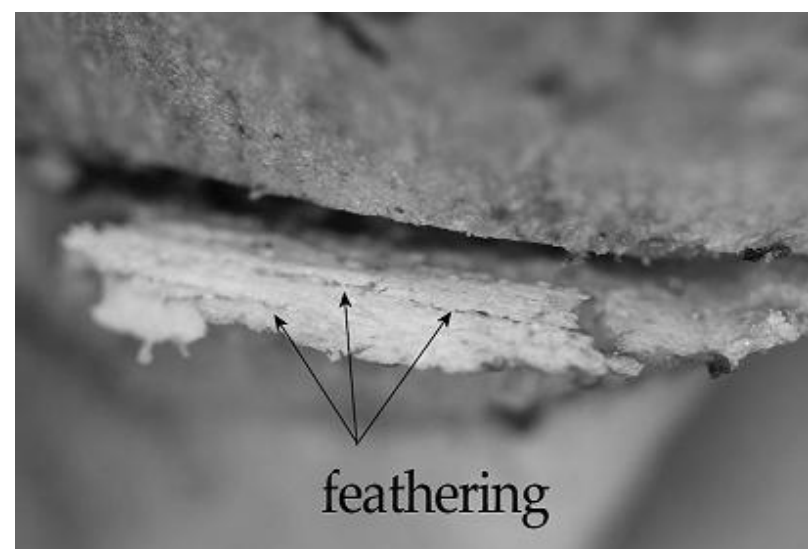

Figure 5: Records the lateral feathering, or rising up, of the external bone in a type of feathering pattern, and is still attached. 
Citation: Cardle PM (2017) Determining the Experience of a Swordsman and Sharpening Methods Based on Bone Cut Marks: A Pilot Study. J Anthropology Rep 2: 114.

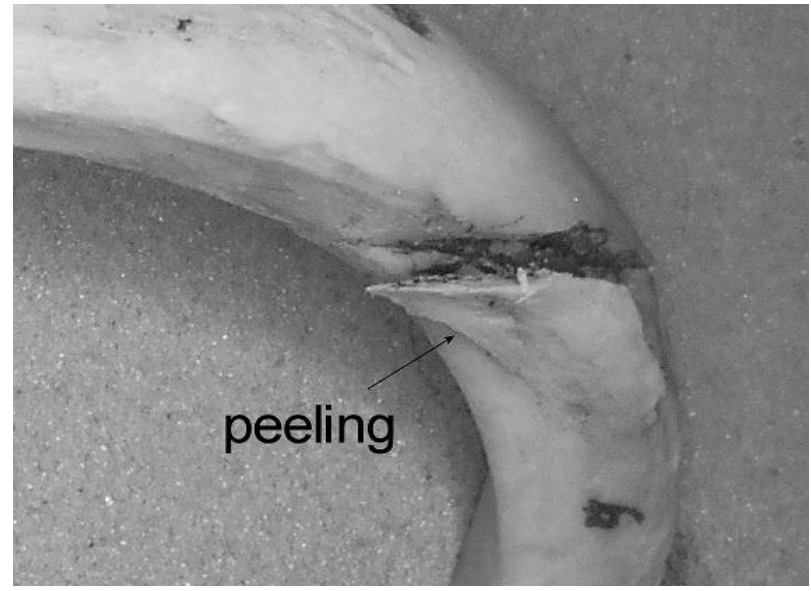

Figure 6: Records the lateral raising or peeling away of the external bone surface next to the cut mark and is still attached to the bone. An infraction (incomplete fracture) that is still attached at an unnatural angle.

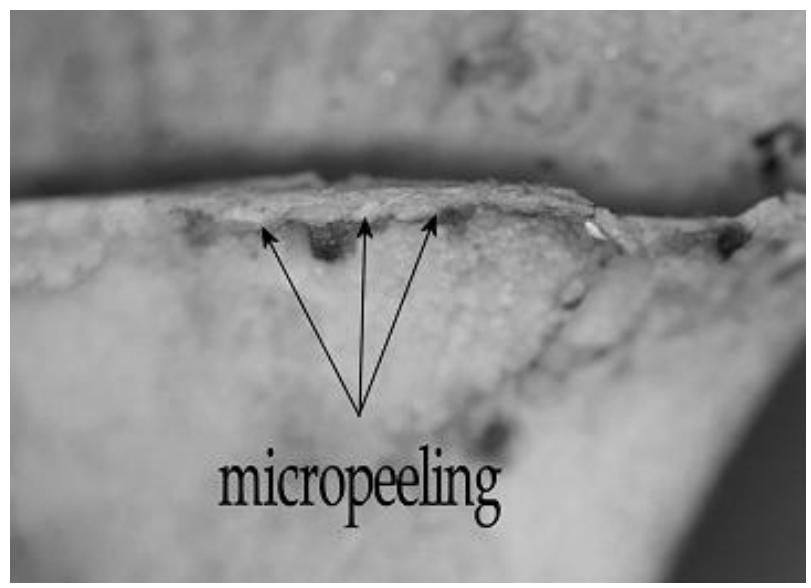

Figure 7: Records the micro lateral raising or peeling away of the external bone surface along the entry the cut mark and is still attached to the bone.

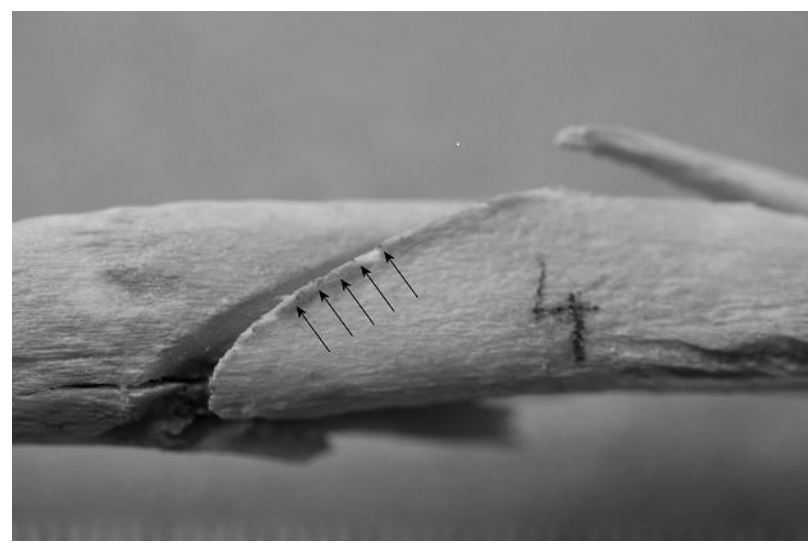

Figure 8: Records the uniform micro curvature of bone at the entry.

This pattern is also evident in the cortical bone of those ribs where the cortical bone survives the hacking and cleaning process (Figures 9 and 10). All spongy bone was also examined under SEM and no clear striations were evident in any of the samples.

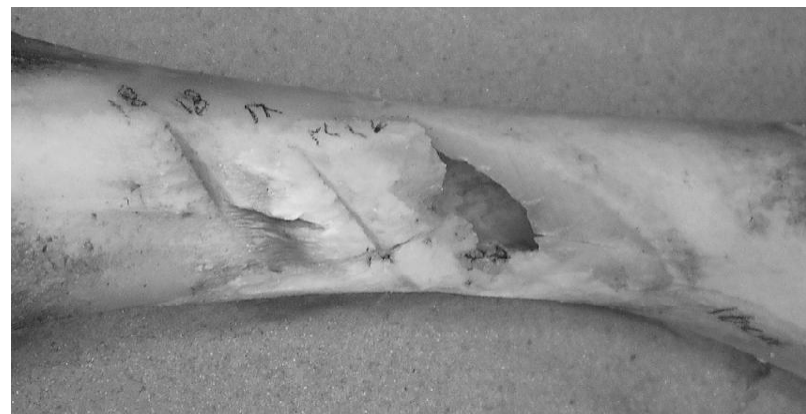

Figure 9: Records the presence of a fragment or wedge of bone removed during the removal of the blade, resulting in a concave defect with multiple facets.

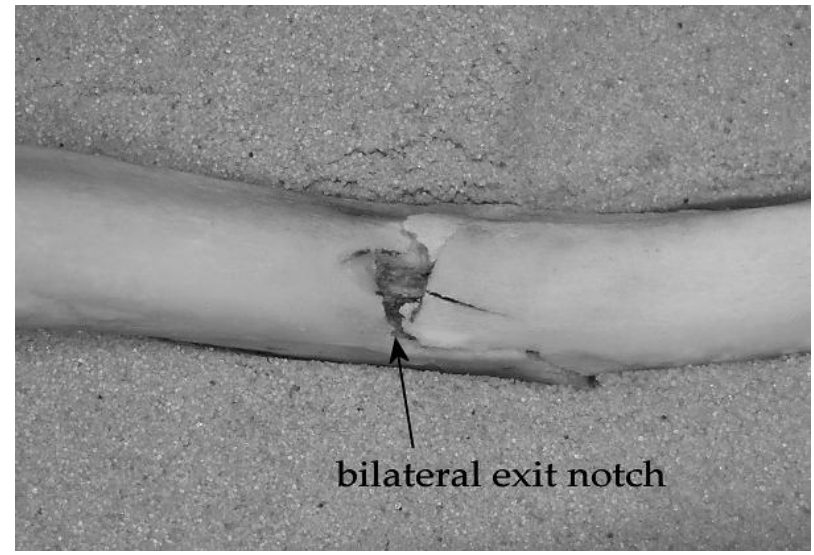

Figure 10: Records the presence of a fragment or wedge of bone removed at the posterior of a complete cut mark.

\section{Discussion}

Visual observations of the cut marks made to ribs, flat and long bones reveal correlations based on the experience of the swordsman and consequently the manner in which the katana is wielded to cut mark morphology, while the method of sharpening is evident in the striations. Seven characteristics of a cut produced by a katana include flaking, feathering, peeling, micro-peeling, micro-curvature, a scoop defect and an exit notch. Of those, micro- curvature was consistently produced by an inexperienced swordsman using a hacking motion. In addition to micro-curvature, the presence of unilateral flaking and a scoop defect on long bones is indicative of being inflicted by an inexperienced swordsman who uses a hacking motion. Unilateral micro curvature is consistently present in all three bones types and appears to be a unique katana characteristic. It is also more often produced by an inexperienced swordsman compared to cuts produced by an experienced swordsman. The presence of flaking, as identified previously by Lewis [3] as being present on long bones, are supported by this research, though rarely present in rib bones. The previously identified incisions and scratches in archaeological specimens were not evident on the samples for this research, however, it is likely that the gashes described in the literature are a scoop defect produced by a hacking motion.

The examination of striations on kerf walls made by a katana has not been previously examined and the results indicate clear and distinct differences in sharpening techniques. A traditionally made and 
Citation: Cardle PM (2017) Determining the Experience of a Swordsman and Sharpening Methods Based on Bone Cut Marks: A Pilot Study. J Anthropology Rep 2: 114.

polished katana wielded in a slicing motion produce smooth, parallel step patterns with a secondary parallel pattern over the first along each step edge. The factory manufactured and sharpened display katana produce rough, mainly parallel striations that have a sharp/pointed edge. The striations were present on both kerf walls.

The small sample size is a limiting factor in the research. Based on the observed sample sizes, a power of $80 \%$ and a significance level of $5 \%$, the corresponding statistical tests have the ability to detect differences of at least $40 \%$ as statistically significant between weapon types for each bone. This implies that differences below these figures may not be picked up as being statistically significant by the associated statistical tests so clinical differences or effect sizes were also an important emphasis of this research. This study can be considered an important pilot study in an area that has had very limited research to date.

\section{Conclusion}

It is possible to distinguish cut marks on bone produced by different large bladed hacking implements. Whilst hacking weapons can produce a wide range of morphologies, they are distinguishable from other classes of bladed weapons and often within their own class. A katana is distinguished by the presence of one or all seven characteristics identified in this research. The presence of micro-curvature is a characteristic produced by an inexperienced swordsman and the rough striations with sharp edges is produced by a factory sharpened katana. While the slicing action of an experienced swordsman produced no specific characteristics identifying it, for cuts made by an experienced swordsman, the striations were unique and were able to identify the weapon as traditionally polished.

In the absence of eyewitness accounts, class and individual characteristics of tool marks may play a major role in weapon identification. This pilot study may further assist in the identification of a katana (traditional or display), trauma action (slicing or hacking) and/or possible sharpening techniques (traditional or factory) further assisting in weapon identification. Such identification has the potential to add another level of scientific inquiry when examining evidence at trials. Additionally, the identification of characteristics (both macro and micro) on flat and rib bones allows for such bones to be included in future research and forensic cases rather than excluded based on an assumption they are not likely to hold any useful information.

\section{References}

1. Humphrey JH, Hutchinson DL (2001) Macroscopic Characteristics of Hacking Trauma. Journal of Forensic Science 46: 228-233.

2. Karasulas A (2004) Zaimokuza reconsidered: The forensic evidence, and classical Japanese swordsmanship.
3. Lewis JE (1980) Identifying Sword Marks on Bone: Criteria for Distinguishing Between Cut Marks Made by Various Classes of Bladed Weapons. Journal of Archaeological Science 35: 1-8.

4. Shackley M (1986) Arms and the Men; 14th Century Japanese Swordsmanship Illustrated by Skeletons from Zaimokuza, Near Kamakura, Japan. World Archaeology 18: 247-254.

5. Wenhan SJ (1989) Anatomical interpretations of Anglo-Saxon weapon injuries In: Hawkes SC (ed.) Weapons and warefare in Anglo-Saxon England. Oxford Committee for Archaeology 21: 123-139.

6. Sakaue K (2010) A Case Report of Human Skeletal Remains Performed "Tameshi-giri (test cutting with a Japanese sword)". Bulletin National Museum Natural Science.

7. Nagaoka T, Mikiko A (2007) Human Skeletal Remains from the Osaka Castle Site in japan: metrics and Weapon Injures. Anthropological Science 115 163-168.

8. Nagaoka T, Hirata K (1992) A decapitated human skull from medieval Kamakura. Anthropological Science 100: 349-358.

9. Nagaoka T, Uzawa K, Hirata K (2009) Weapon-related Traumas in Human Skeletons from Yuigahama Chusei Shudan Bochi, Japan. Anatomical Science International 84: 170-181.

10. Nagaoka To, Abe M (2007) Human Skeletal Remains from the Osaka Castle Site in Japan: metrics and weapon injuries. Anthropological Science 163-168.

11. Morimoto I (1987) Note on the Technique of Decapitation in Medieval Japan. Journal of Anthropological Society, Nippon 95: 477-486.

12. Suzuki H, Hayashi H, Tanabe G, Sakura H (1956) Medieval Japanese skeletons from the burial site at Zaimokuza, Kamakura City. Tokyo, Japan Anthropological Society of Nippon, Iwanami Shoten.

13. Symes SA, Hugh EB, Smith OC (1998) Saw marks in bone: introduction and examination of residual kerf contour. In: Reichs KJ (ed.) Forensic Osteology II. Advances in the Identification of Human Remains. Springfield.

14. Tucker BK, Dale L, Hutchinson DL, Gilliland MFG, Charles TM (2001) Microscopic Characteristics of Hacking Trauma. Journal of Forensic Science 46: $234-240$

15. Wakley J (1993) The uses of scanning electron microscopy in the interpretation of some examples of trauma in human skeletal.

16. Wakley J, Bruce MF (1989) Interpreting Signs of Trauma on a Human Axis Vertebra. Journal of Anatomy 6: 92-100.

17. Wenham SJ, Wakley J (1989) Microscopic Features of Blade-injuries to Bone surfaces in six Anglo-Saxon skeletons from Eccles Kent, Roberts CA Lee $\mathrm{F}$, Bintliff $\mathrm{J}$ (eds.), Burial archaeology current research, methods and developments British archaeological reports. British Series.

18. InAlunni-Perret V, Muller Bolla M, Laugier J, Lupi-Pegurier L, Bertrand M, et al (2005) Scanning Electron Microscopy Analysis of Experimental Bone Hacking Traima. Journal of Forensic Science.

19. IBM Corporation (2016) IBM SPSS Statistics for Windows 